Author affiliations and support information (if applicable) appear at the end of this article.

Published at jco.org on September 6, 2018

J.W., M.C.L.D., I.J., I.L., A.C., H.J., and O.O. contributed equally to this work.

Clinical trial information: NCT00987636

Corresponding author: Jeremy Whelan, $\mathrm{MD}$, University College Hospital London, 250 Euston Rd, London, NW1 2PG,

United Kingdom; e-mail: Jeremy.whelan@ nhs.net.

(C) 2018 by American Society of Clinical Oncology

0732-183X/18/3631w-3110w/\$20.00

\title{
High-Dose Chemotherapy and Blood Autologous Stem-Cell Rescue Compared With Standard Chemotherapy in Localized High-Risk Ewing Sarcoma: Results of Euro-E.W.I.N.G.99 and Ewing-2008
}

Jeremy Whelan, Marie-Cecile Le Deley, Uta Dirksen, Gwénaël Le Teuff, Bernadette Brennan, Nathalie Gaspar, Douglas S. Hawkins, Susanne Amler, Sebastian Bauer, Stefan Bielack, Jean-Yves Blay, Stefan Burdach, Marie-Pierre Castex, Dagmar Dilloo, Angelika Eggert, Hans Gelderblom, Jean-Claude Gentet, Wolfgang Hartmann, Wolf-Achim Hassenpflug, Lars Hjorth, Marta Jimenez, Thomas Klingebiel, Udo Kontny, Jarmila Kruseova, Ruth Ladenstein, Valerie Laurence, Cyril Lervat, Perrine Marec-Berard, Sandrine Marreaud, Jean Michon, Bruce Morland, Michael Paulussen, Andreas Ranft, Peter Reichardt, Hendrik van den Berg, Keith Wheatley, Ian Judson, Ian Lewis, Alan Craft, Heribert Juergens, and Odile Oberlin, on behalf of the Euro-E.W.I.N.G.99 and EWING-2008 Investigators

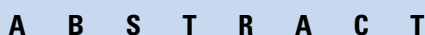

\section{Purpose}

For over 30 years, the place of consolidation high-dose chemotherapy in Ewing sarcoma (ES) has been controversial. A randomized study was conducted to determine whether consolidation high-dose chemotherapy improved survival in patients with localized ES at high risk for relapse.

\section{Methods}

Randomization between busulfan and melphalan (BuMel) or standard chemotherapy (vincristine, dactinomycin, and ifosfamide [VAl], seven courses) was offered to patients if they were younger than 50 years of age with poor histologic response ( $\geq 10 \%$ viable cells) after receiving vincristine, ifosfamide, doxorubicin, and etoposide (six courses); or had a tumor volume at diagnosis $\geq 200 \mathrm{~mL}$ if unresected, or initially resected, or resected after radiotherapy. A 15\% improvement in 3-year eventfree survival (EFS) was sought (hazard ratio [HR], 0.60).

\section{Results}

Between 2000 and 2015, 240 patients classified as high risk (median age, 17.1 years) were randomly assigned to VAI $(n=118$ ) or BuMel $(n=122)$. Seventy-eight percent entered the trial because of poor histologic response after chemotherapy alone. Median follow-up was 7.8 years. In an intent-to-treat analysis, the risk of event was significantly decreased by BuMel compared with VAl: $\mathrm{HR}, 0.64(95 \% \mathrm{Cl}$, 0.43 to $0.95 ; P=.026)$; 3- and 8-year EFS were, respectively, $69.0 \%(95 \% \mathrm{Cl}, 60.2 \%$ to $76.6 \%)$ versus $56.7 \%(95 \% \mathrm{Cl}, 47.6 \%$ to $65.4 \%)$ and $60.7 \%(95 \% \mathrm{Cl}, 51.1 \%$ to $69.6 \%)$ versus $47.1 \%(95 \% \mathrm{Cl}, 37.7 \%$ to $56.8 \%)$. Overall survival (OS) also favored BuMel: $\mathrm{HR}, 0.63(95 \% \mathrm{Cl}, 0.41$ to $0.95 ; P=.028) ; 3$ - and 8-year OS were, respectively, $78.0 \%(95 \% \mathrm{Cl}, 69.6 \%$ to $84.5 \%)$ versus $72.2 \%(95 \% \mathrm{Cl}, 63.3 \%$ to $79.6 \%$ ) and $64.5 \%(95 \% \mathrm{Cl}, 54.4 \%$ to $73.5 \%$ ) versus $55.6 \%$ (95\% Cl, 45.8\% to $65.1 \%)$. Results were consistent in the sensitivity analysis. Two patients died as a result of BuMel-related toxicity, one after standard chemotherapy. Significantly more BuMel patients experienced severe acute toxicities from this course of chemotherapy compared with multiple VAl courses.

\section{Conclusion}

BuMel improved EFS and OS when given after vincristine, ifosfamide, doxorubicin, and etoposide induction in localized ES with predefined high-risk factors. For this group of patients, BuMel may be an important addition to the standard of care.

\section{J Clin Oncol 36:3110-3119. @ 2018 by American Society of Clinical Oncology}

\section{INTRODUCTION}

Treatment advances in Ewing sarcoma (ES) have largely resulted from a multidisciplinary approach to clinical trials conducted by national and international cooperative groups. Over the years, these trials have answered key chemotherapy questions and better defined risk groups, allowing tailored treatment strategies. Prolonged disease-free 
survival is achieved in the majority of patients with localized ES after treatment with multiagent chemotherapy and primary tumor control. ${ }^{1-4}$ Larger initial tumor volume is a well-defined adverse prognostic factor, ${ }^{5-8}$ the predictive power of which is over-ridden by the extent of histologically determined chemotherapy-induced necrosis assessed in resected primary tumors. ${ }^{4,8-11}$ These observations can be used to define subgroups of patients with localized ES in whom treatment interventions to improve survival may be examined.

The rationale for high-dose therapy (HDT) in ES was developed to exploit an alkylating agent dose-response relationship. Several single-arm studies have indicated high-dose chemotherapy efficacy using historical controls in newly diagnosed metastatic or recurrent ES, using various drugs or combinations with or without total-body irradiation. ${ }^{12-18}$ Two national nonrandomized studies evaluated the role of busulfan-melphalan (BuMel) in patients with poor histologic response and suggested its potential benefit compared with historical controls treated with conventional chemotherapy. ${ }^{19,20}$ Because these encouraging results were based on uncontrolled comparisons, a randomized comparison of high-dose chemotherapy against standard chemotherapy was therefore incorporated in two multinational controlled trials, EuroE.W.I.N.G.99 and EWING-2008. In the selected high-risk population, termed R2Loc, the primary objective was to evaluate whether HDT using BuMel improved event-free survival (EFS) compared with standard chemotherapy (vincristine, dactinomycin, ifosfamide [VAI]).

\section{METHODS}

\section{Study Design}

The R2Loc trial was an international, randomized, superiority trial comparing consolidation treatment with BuMel or seven VAI courses in a two-parallel-group design. The R2Loc randomized trial was a component of the Euro-E.W.I.N.G.99 study (ClinicalTrials.gov identifier: NCT00020566) recruiting all patients with ES at diagnosis, enrolled by four cooperative groups: European Organization for Research and Treatment of Cancer (EORTC), Gesellschaft für Pädiatrische Onkologie und Hämatologie $(\mathrm{GPOH})$, French Society of Pediatric Oncology and French Sarcoma Group, and the UK Children's Cancer and Leukaemia Group. ${ }^{1,21,22}$ From May 2010, patients from GPOH were recruited in the same R2Loc randomized trial conducted through the EWING-2008 study (ClinicalTrials.gov identifier: NCT00987636).

\section{Patients}

Eligibility requirements were age younger than 50 years; enrollment at diagnosis either in Euro-E.W.I.N.G.99 or EWING-2008 studies for newly diagnosed biopsy-proven ES; localized disease classified as high risk because of poor histologic response to induction chemotherapy (residual viable cells $\geq 10 \%$ ) for patients undergoing surgery after induction chemotherapy alone or because of large tumor volume at diagnosis $(\geq 200 \mathrm{~mL})$ in unresected or initially resected tumors or resected tumors with preoperative irradiation, but patients with a small unresected tumor were also eligible in case of poor clinical response to induction chemotherapy $(<50 \%$ radiologic reduction in soft tissue disease component); and no medical contraindication to treatment. After amendment, because of busulfan-related radiosensitivity, ${ }^{23}$ patients expected to receive radiotherapy $>30$ Gy to the spinal cord (Amendment July 2004) or $>45$ Gy to large intestinal volume (Amendment November 2008) were no longer eligible. Written informed consent was obtained from all patients and/or their parents/guardians before enrollment.

\section{Treatments}

Induction chemotherapy consisted of six chemotherapy courses combining vincristine, ifosfamide, doxorubicin, and etoposide (VIDE). ${ }^{21,24}$ After one VAI course, allocated consolidation treatment was either seven VAI courses (VAI arm) or one course of high-dose BuMel chemotherapy with autologous stem-cell transplant (BuMel arm). Treatment schedule and chemotherapy details are in the Data Supplement.

Local therapy was tailored to patient and tumor characteristics, and included surgery with complete surgical removal wherever feasible, radiotherapy, or a combination of both (Data Supplement). Stem-cell harvest was undertaken according to local practice after VIDE course 2.

\section{Randomization}

Random assignment was performed after six VIDE courses plus one VAI consolidation course, after surgery and assessment of histologic response when applicable. Randomization was balanced and stratified according to cooperative group, sex, age (younger than 25 years), and local treatment (resection after chemotherapy alone with or without postoperative radiotherapy $v$ initial surgery $v$ resection after chemotherapy and radiotherapy $v$ radiotherapy only). Centralized randomization software was used in all data centers, ensuring the concealment of the next patient allocation. The GPOH data center used permuted blocks of four. In the other data centers, randomization was also balanced by the treating center using dynamic allocation of treatment (minimization with a random factor set at 0.8 ).

\section{End Points and Assessments}

The primary end point was EFS, defined as the time from randomization to the date of the first failure assessed by the investigator (progression, relapse, second malignancy, or death, whatever the cause). Follow-up was planned every 3 months during the first 3 years, every 6 months during years 4 and 5, then yearly, regardless of treatment compliance. Overall survival (OS) since randomization was a secondary efficacy end point, considering all deaths, whatever the cause.

Central imaging review of tumor volume and response, and pathologic review were not undertaken. Compliance with treatment and toxicity were monitored. All chemotherapy doses were recorded, as well as the reasons for dose reduction or delay. Acute toxicity related to chemotherapy was assessed after each course, using a list of 22 selected items from the National Cancer Institute Common Toxicity Criteria version 2.0 and Bearman's criteria for sinusoidal obstruction syndrome. ${ }^{25}$ Other adverse reactions were specified. A modified list was used to evaluate toxicity after radiotherapy, using Radiation Therapy Oncology Group classification for 17 toxicities. ${ }^{26}$ For each toxicity type, the maximum grade observed over the whole maintenance treatment was computed, including radiotherapy to the primary site. Grade 4 hematologic toxicities and grade 3 or higher of all nonhematologic toxicities were considered severe.

\section{Statistical Analysis}

The study was designed to ensure $80 \%$ power for a $40 \%$ reduction in the risk of an event in the BuMel arm compared with the VAI arm (expected 3-year EFS, 70\% v 55\%; hazard ratio [HR], 0.60) with a two-sided log-rank test $\alpha$ of .05 . The initial target sample size was 328 patients (124 events). ${ }^{27}$ With support from the independent data monitoring committee, recruitment was stopped before reaching this target because of low accrual. This is the final analysis, on the basis of data as of July 2016.

Preplanned efficacy stopping rules were defined using the $\alpha$ spending function approach with O'Brien-Fleming boundaries. ${ }^{28,29}$ These analyses were only disclosed to the independent monitoring committee. Survival rates (EFS and OS) were estimated using the Kaplan-Meier method with Rothman's 95\% CIs. Median follow-up was estimated using the reverse Kaplan-Meier method. The HR of event (EFS) and the HR of death (OS) were estimated in Cox models. The point estimate of the HR of event, its $\mathrm{CI}$, and the $P$ value were corrected for the four previous interim analyses 


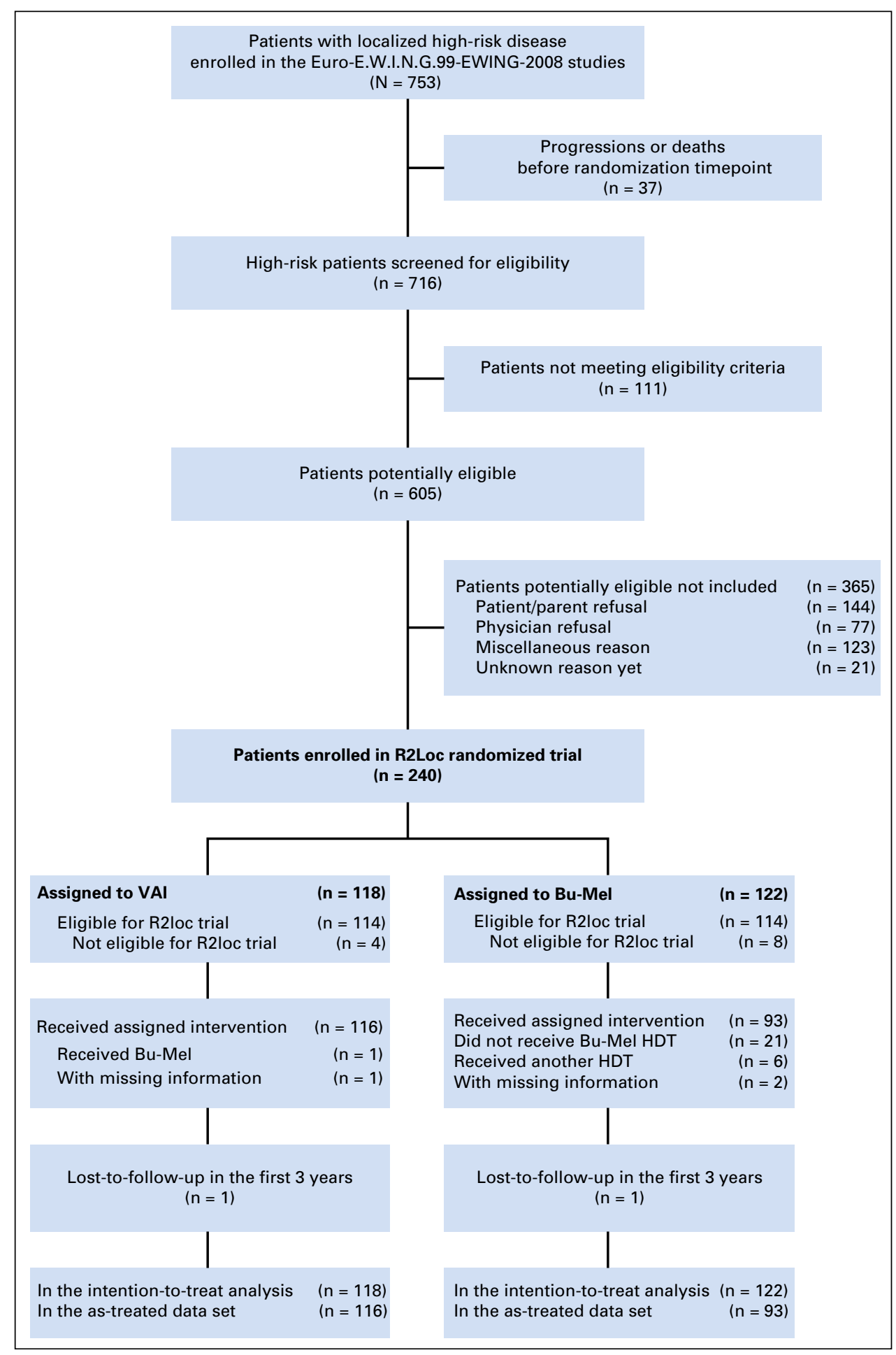

Fig 1. Trial profile. A total of 111 patients with disease classified as localized high-risk disease assessed for eligibility did not meet eligibility criteria: insufficient diagnosis criteria or diagnosis rejected $(n=14)$; persisting toxicity related to previous treatment and/or contraindication to planned treatment $(n=78)$, including contraindication to busulfan and melphalan (BuMel) because of planned radiotherapy to an axial site $(n=36)$; early radiotherapy ( $n=13$ ); psychological problems $(n=6) ; 123$ patients meeting eligibility criteria were not enrolled because of other reasons. HDT, high dose therapy; R2Loc, selected highrisk population; VAl, vincristine, dactinomycin, and ifosfamide.

using the inverse normal method. ${ }^{31}$ The primary efficacy analysis was performed according to the patients' randomly assigned treatments (ie, by intention-to-treat population). Post hoc sensitivity analyses were performed, (1) adjusting for age (in four categories: $<12,12$ to 18,18 to $25,>25$ years) and (2) excluding patients with a major treatment modification (as-treated; Data Supplement). The heterogeneity of treatment effect (BuMel $v$ VAI) on EFS according to stratification variables and tumor volume, tumor site, and histologic response (post hoc exploratory analysis) were evaluated in multivariable models, including interaction terms, and illustrated in a forest plot. Because the EFS is a composite end point, a competing risk approach was also used to estimate the effect of treatment on the risk of metastases using subdistribution HRs considered competing events: local progression/ relapse without concomitant metastases, secondary malignancy, and death without prior metastases (post hoc analysis). ${ }^{32,33}$

Safety analyses were performed on the safety set, excluding patients who did not receive the assigned treatment (as-treated population). For 


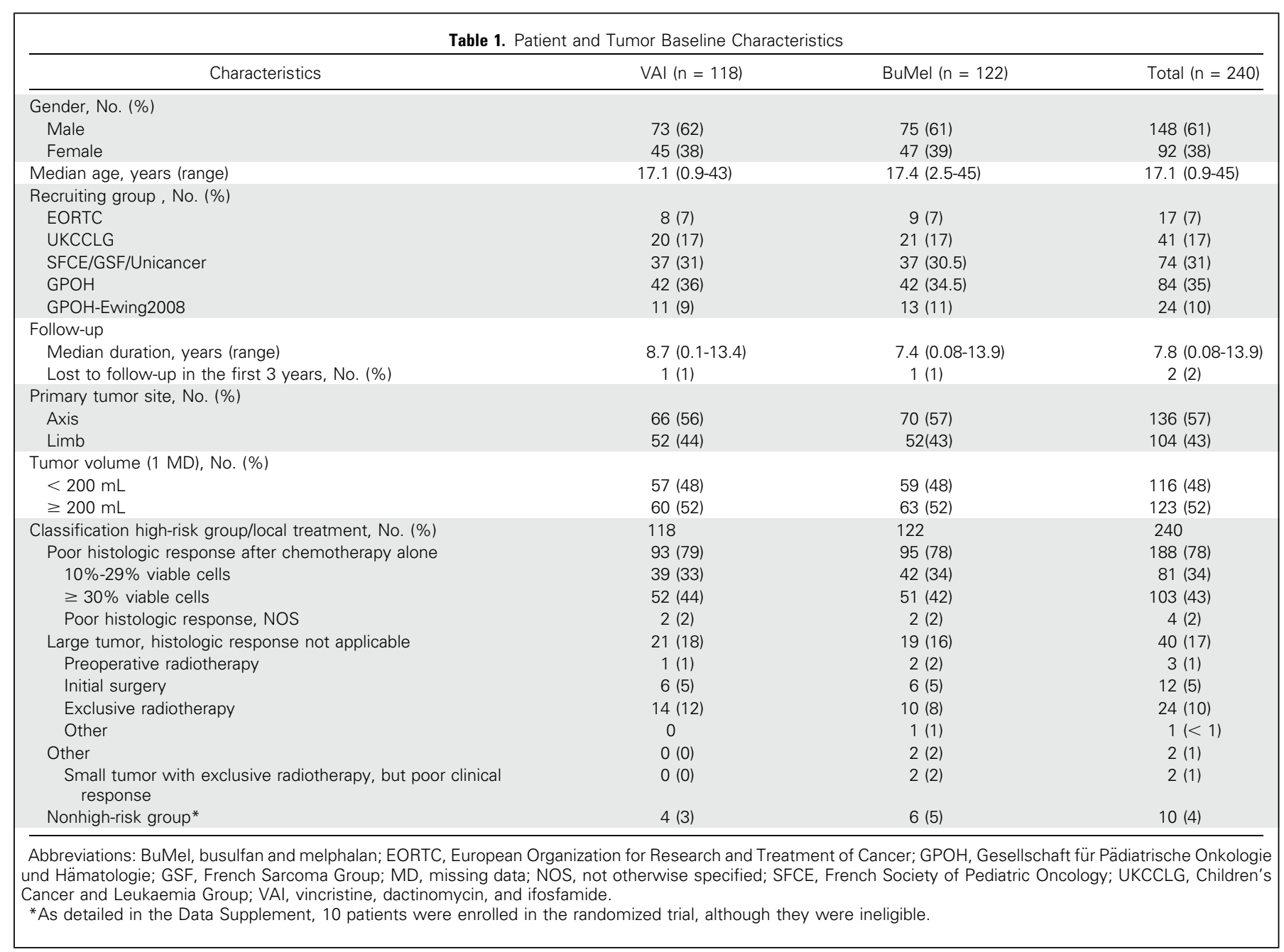

each toxicity category, the relative risk of having experienced a severe toxicity in BuMel versus VAI was estimated.

Estimates are provided with 95\% CIs. All tests are two sided. The analyses were performed using SAS 9.3 software (SAS Institute, Cary, NC).

\section{Study Oversight}

Study protocols were approved by an independent ethics committee and the appropriate institutional review boards. The studies were conducted in accordance with the ethical principles of the Declaration of Helsinki and with Good Clinical Practice guidelines. The trial was designed jointly by the senior academic authors from the participating cooperative groups. The protocols are available online. Data were analyzed by the biostatisticians at Institut Gustave Roussy and reviewed by the statisticians' board. The first draft of this article was written by M.C.L.D., O.O., and J.W. All authors contributed to subsequent drafts and made the decision to submit the manuscript for publication. None of the funders had a role in study design, collection, analysis, or interpretation of data.

\section{RESULTS}

\section{Patients}

Between February 2000 and December 2015, 716 patients with a localized tumor fulfilling the predefined high-risk criteria, enrolled in 131 centers from 13 countries, were assessed for eligibility. Among them, 111 did not meet eligibility criteria (details in the legend of Fig 1). Of 605 eligible patients, 221 were not enrolled because of patient/parent $(\mathrm{n}=144)$ or physician $(\mathrm{n}=$ 77) refusal, 123 for other reasons, and 21 for whom the reason was unknown; 240 patients were included in the randomized trial: 118 assigned to VAI and 122 assigned to BuMel (Fig 1). The median age was 17.1 years (range, 11 months to 44.7 years). The baseline characteristics were well balanced between the two groups (Table 1), although over the course of the study, some changes were notable, with a greater proportion with less favorable histologic response represented (Data Supplement). Overall, 188 of the 240 patients (78\%) entered the trial because of poor histologic response after chemotherapy alone. Median followup was 7.8 years and was not significantly different between treatment groups (Data Supplement). Among the 240 enrolled patients, four patients in the VAI arm and eight patients in the BuMel arm were not eligible (Data Supplement).

One patient allocated to VAI received BuMel on his request. In the BuMel arm, 21 patients did not receive any HDT because of patient refusal $(n=11)$, medical reason $(n=7)$, physician decision $(n=2)$, or failure to collect peripheral stem cells $(n=1)$; six patients received HDT other than BuMel because of physician decision in five 
A

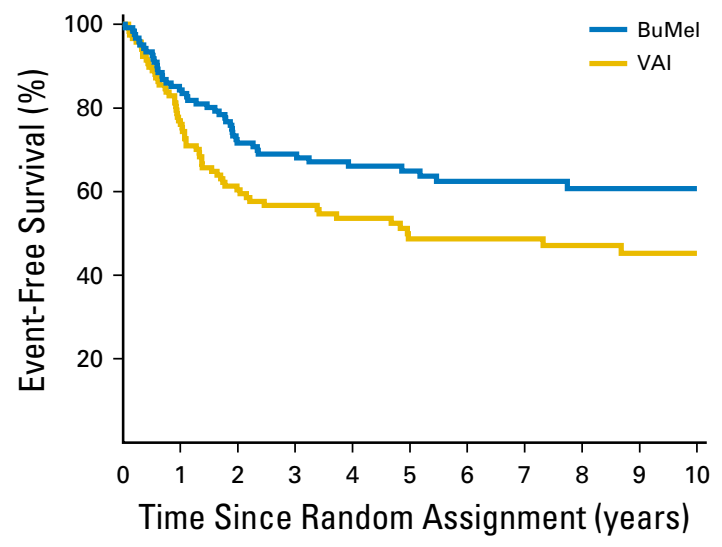

No. at risk:

$\begin{array}{lllllll}\text { BuMel } & 122 & 84 & 62 & 48 & 33 & 16\end{array}$

C

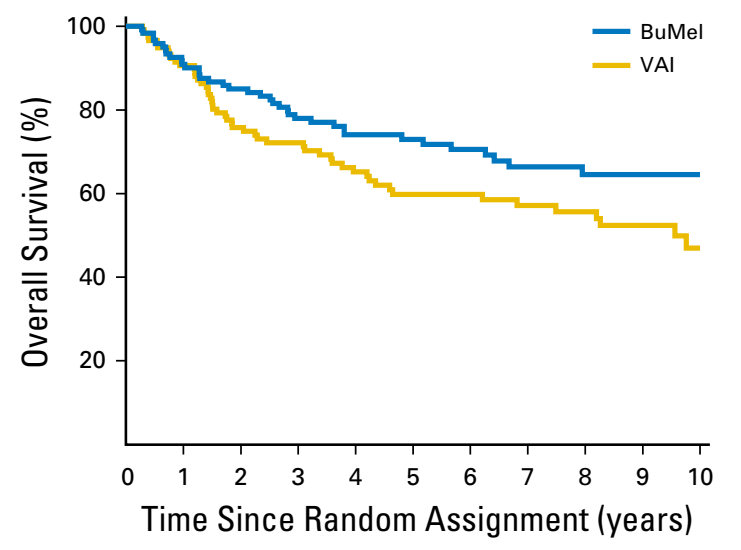

No. at risk:

$\begin{array}{lllllll}\text { BuMel } & 122 & 100 & 72 & 55 & 35 & 18 \\ \text { VAl } & 118 & 85 & 63 & 48 & 35 & 14\end{array}$

B

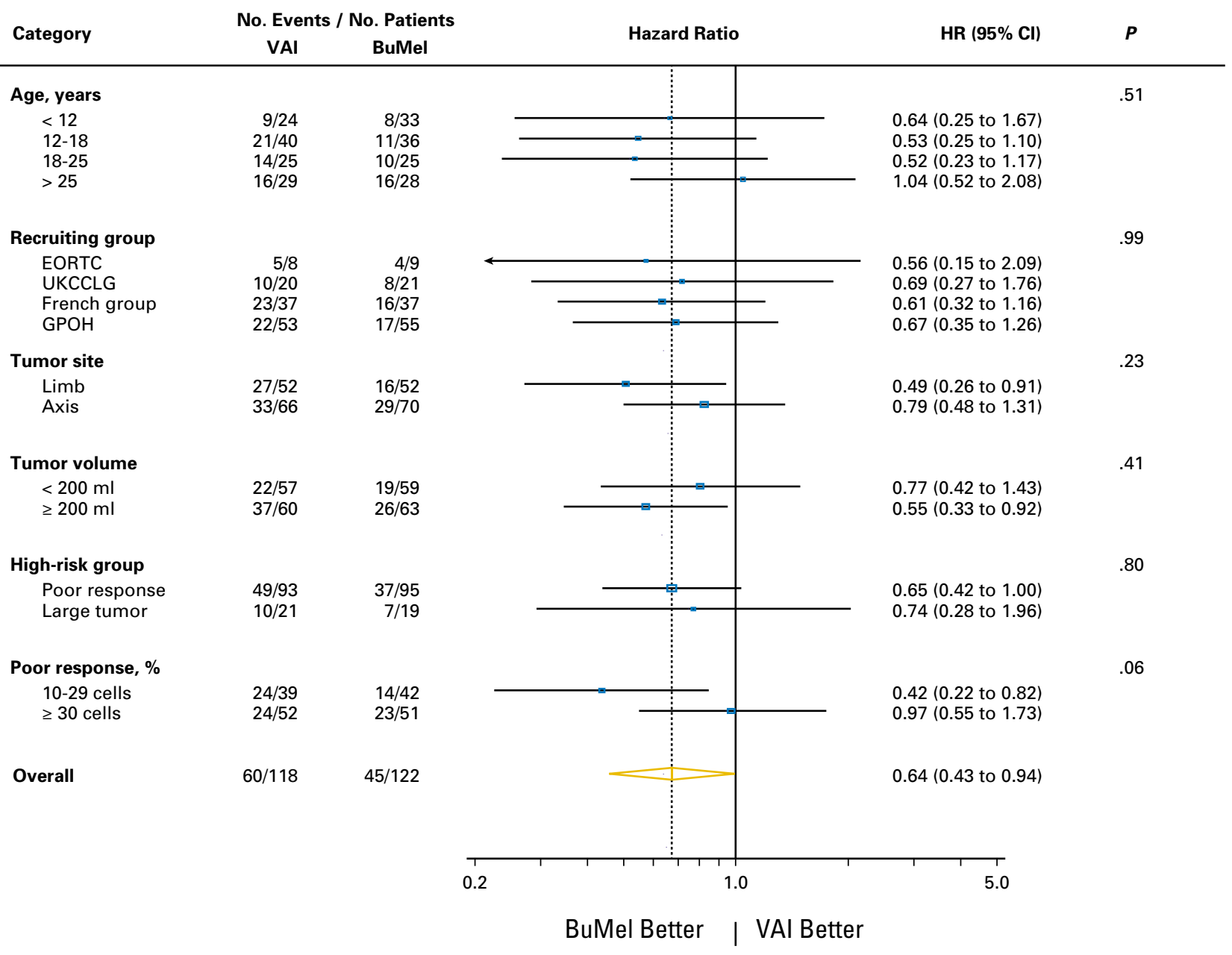

Fig 2. (A and B) Event-free survival (EFS) and (C) overall survival. (A) Kaplan-Meier estimates of EFS by treatment group, on the intention-to-treat (ITT) population.

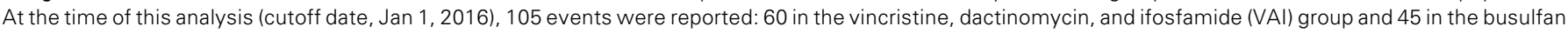

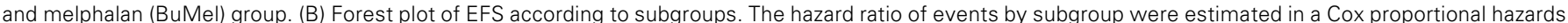

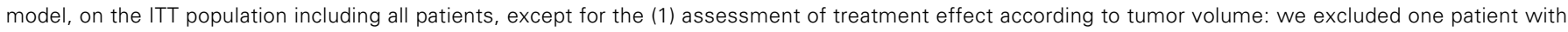

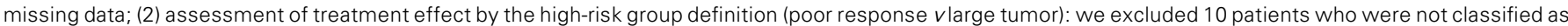

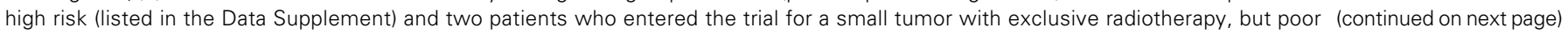


patients and BuMel contraindication in one patient (Data Supplement). These 28 patients were excluded in the as-treated analysis.

When grouped by selected factors, the proportions of patients randomly assigned to those not randomly assigned varied (data not shown). There were differences by study year, study group, age, tumor volume, histologic response, and treatment with radiotherapy.

\section{Efficacy}

A total of 105 events were reported (VAI arm, 60; BuMel arm, 45): 13 local progressions or local relapses, 80 distant metastases (including lung metastases in 51 patients), five secondary malignancies, and seven deaths as first events (Data Supplement), including three treatment-related deaths.

EFS for all 240 randomly assigned patients was $62.9 \%(95 \%$ CI, $56.6 \%$ to $68.9 \%$ ) at 3 years and $54.0 \%$ (95\% CI, $47.2 \%$ to $60.7 \%)$ at 8 years. The treatment effect of BuMel was estimated as an HR of 0.64 (95\% CI, 0.43 to $0.95 ; P=.026)$, corrected for the four previous interim analyses. Three-year EFS rates for VAI and BuMel were $56.7 \%$ (95\% CI, $47.6 \%$ to $65.4 \%$ ) and $69.0 \%$ (95\% CI, $60.2 \%$ to $76.6 \%$ ), respectively, with this improvement being sustained at 8 years: $47.1 \%(95 \% \mathrm{CI}, 37.7 \%$ to $56.8 \%)$ versus $60.7 \%$ (95\% CI, $51.1 \%$ to $69.6 \%$; Fig 2A; Table 2), respectively. The treatment effect estimate seems greater in the sensitivity analysis, when patients with protocol violations were excluded (Table 2). As illustrated in Figure 2B, no significant heterogeneity of the treatment effect was observed according to cooperative group, tumor site, tumor volume, or eligibility criteria for high-risk classification. However, patients with an intermediate poor response may benefit more than those with a very poor response ( $10 \%$ to $29 \% v \geq 30 \%$ viable cells; interaction test, $P=.06)$, as well as older patients ( $\leq 25 v>25$ years of age; $P=.12$ ). Improvement in EFS was mostly related to a reduction in the risk of metastases (subdistribution-HR, 0.58; 95\% CI, 0.37 to $0.90 ; P=.02$; Data Supplement).

Benefit from BuMel was also observed in OS. Ninety deaths were reported (VAI, 53; BuMel, 37), leading to an HR of 0.63 (95\% CI, 0.41 to $0.95 ; P=.028)$. Three-year OS was $72.2 \%(95 \% \mathrm{CI}$, $63.3 \%$ to $79.6 \%$ ) and $78.0 \%$ (95\% CI, $69.6 \%$ to $84.5 \%$ ) for VAI and BuMel, respectively (Fig 2C), and 75.1\% (95\% CI, 69.2\% to 80.2\%) overall. Eight-year OS was $55.6 \%$ (95\% CI, $45.8 \%$ to $65.1 \%$ ) versus $64.5 \%$ (95\% CI, $54.4 \%$ to $73.5 \%)$.

\section{Safety}

Significantly more BuMel patients experienced severe acute toxicities (Fig 3), but toxicity arose from a single high-dose course versus multiple VAI courses (Data Supplement). The effect of BuMel on the risk of severe acute toxicity did not differ between patients older than 25 years and younger patients (Data Supplement). Three treatment-related deaths were reported in the BuMel arm, although one was in a patient who did not receive BuMel because of renal dysfunction. One patient with a cervical spine primary site died as a result of myelopathy related to radiotherapy administered after BuMel, and one patient with a chest wall primary site died as a result of acute respiratory distress syndrome associated with pancytopenia 5 months after receiving BuMel.

\section{DISCUSSION}

In the subgroup of patients with localized ES specifically defined for this study, treatment with BuMel conferred a significant, sustained, and clinically meaningful improvement (European Society for Medical Oncology-Magnitude of Clinical Benefit Scale grade A) in EFS and OS. ${ }^{34}$ This outcome was despite the final analysis being conducted after recruitment of only 240 of a planned 328 patients and was sustained with prolonged follow-up. This finding is particularly significant, given the observation that cure rates in this important cancer of children and young people have improved modestly at best over recent decades and that the expanding knowledge of the biology of ES has, to date, not resulted in the introduction of new agents into standard care. ${ }^{35}$

Several factors deserve more detailed consideration. First, this was a complex but pragmatic trial performed by an experienced multinational cooperative group that encompassed a large proportion of major pediatric and sarcoma-treating centers in Europe. Despite this, recruitment fell short of the recruitment rates proposed at study initiation. The study was closed before the planned event/patient target was reached because of some investigators' concerns that rates of participation in the study were too low to be sustainable. Of patients within the study registration cohort, one third of those fulfilling the definition of localized high-risk disease were ultimately randomly assigned, with evidence of low acceptability of the study question to both clinicians and patients. We acknowledge that this limits the external validity of our findings. However the description of a screened population and the estimate of randomization rate are missing from other studies, and sets this intervention into a clinically meaningful context.

The use of histologic response as the main selection criterion identifies a population of patients with some degree of initial drug resistance. In R2Loc, this is supplemented by other high-risk patients, accounting for $20 \%$ of randomly assigned patients, for whom histologic response was not available, those with tumors $>200 \mathrm{~mL}$ who had undergone primary surgery or had early radiotherapy or exclusive radiotherapy. This subset of patients may include patients with unidentifiable good response to induction chemotherapy. Overall, the BuMel effect seemed consistent across main strata (cooperative group, tumor site, tumor volume, or eligibility criteria for high-risk classification). Within the poor histologic response spectrum, it is possible that BuMel may have less benefit in those with poor response, although, given that this was an observation from a post hoc exploratory analysis, it is insufficient evidence to be

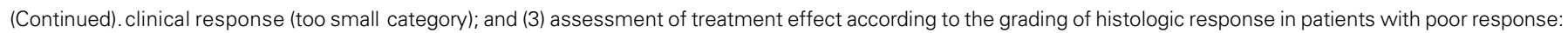

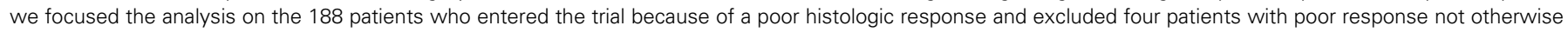

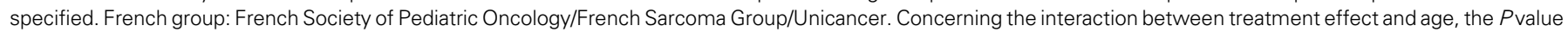

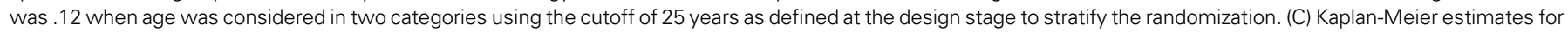

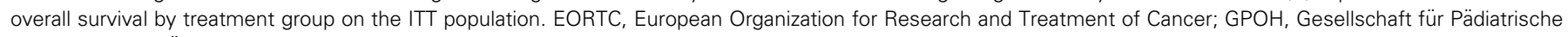
Onkologie und Hämatologie; UKCCLG, UK Children's Cancer and Leukaemia Group 
Table 2. EFS and Overall Survival Analysis, Main Analysis on the Intention-To-Treat Population, and Sensitivity Analysis on the As-Treated Population

\begin{tabular}{|c|c|c|c|c|}
\hline \multirow[b]{2}{*}{ Outcome } & \multicolumn{2}{|c|}{ Intention-To-Treat Analysis } & \multicolumn{2}{|c|}{ As-Treated Population* } \\
\hline & VAl Arm ( $n=118)$ & $\begin{array}{l}\text { BuMel Arm } \\
(n=122)\end{array}$ & VAl Arm, $n=116$ & BuMel Arm ( $n=93$ ) \\
\hline \multicolumn{5}{|l|}{ EFS } \\
\hline No. and type of events & 60 & 45 & 60 & 33 \\
\hline Progression/relapse & 56 & 37 & 56 & 27 \\
\hline Local progression or relapse & 8 & 5 & 8 & 4 \\
\hline Without metastases & 48 & 32 & 48 & 23 \\
\hline \multicolumn{5}{|l|}{$\begin{array}{l}\text { With or without local } \\
\text { progression or relapse }\end{array}$} \\
\hline Secondary malignancy & 3 & 2 & 3 & 2 \\
\hline Death as first reported event $\dagger$ & 1 & 6 & 1 & 4 \\
\hline Treatment-related death & 0 & $3 \ddagger$ & 0 & 2 \\
\hline Death from other cause & 1 & $2 \S$ & 1 & 1 \\
\hline Death from unknown cause & 0 & 1 & 0 & 1 \\
\hline $\begin{array}{l}\text { 3-year EFS since } \\
\text { randomization, \% }(95 \% \mathrm{Cl})\end{array}$ & 56.7 (47.6 to 65.4 ) & $69.0(60.2$ to 76.6$)$ & 56.0 (46.8 to 64.8 ) & 71.7 (61.8 to 79.9$)$ \\
\hline $\begin{array}{l}\text { 8-year EFS since } \\
\text { randomization, \% }(95 \% \mathrm{Cl})\end{array}$ & 47.1 (37.7 to 56.8 ) & 60.7 (51.1 to 69.6) & 46.3 (36.8 to 56.0 ) & 62.8 (51.9 to 72.6$)$ \\
\hline HR of event $(95 \% \mathrm{CI}) \|$ & 1 & $0.64(0.43$ to 0.95$) \uparrow$ & 1 & $0.57(0.37$ to 0.88$)$ \\
\hline$P$ & & $.026 \#$ & & .010 \\
\hline Adjusted HR of event $(95 \% \mathrm{Cl}) \#$ & 1 & $0.65(0.44$ to 0.96$)$ & 1 & 0.58 (0.38 to 0.89$)$ \\
\hline$P$ & & .032 & & .012 \\
\hline \multicolumn{5}{|l|}{ Overall survival } \\
\hline No. and cause of deaths & 53 & 37 & 53 & 28 \\
\hline Due to progression/relapse & 48 & 31 & 48 & 24 \\
\hline Treatment-related death & 0 & $3 \S$ & 0 & 2 \\
\hline Secondary malignancy & 4 & 0 & 4 & 0 \\
\hline Other cause & 1 & $2 \|$ & 1 & 1 \\
\hline Unknown cause & & 1 & & 1 \\
\hline $\begin{array}{l}\text { 3-y OS from randomization, \% } \\
(95 \% \mathrm{Cl})\end{array}$ & $72.2(63.3$ to 79.6$)$ & 78.0 (69.6 to 84.5) & 71.7 (62.8 to 79.2$)$ & 79.2 (69.8 to 86.3) \\
\hline $\begin{array}{l}\text { 8-y OS from randomization, \% } \\
(95 \% \mathrm{Cl})\end{array}$ & 55.6 (45.8 to 65.1$)$ & 64.5 (54.4 to 73.5$)$ & 55.0 (45.1 to 64.5$)$ & 65.4 (54.1 to $75.3 \%)$ \\
\hline HR of death $(95 \% \mathrm{Cl}) \|$ & 1 & $0.63(0.41$ to 0.95$)$ & 1 & $0.58(0.37$ to 0.92$)$ \\
\hline$P$ & & .028 & & .019 \\
\hline $\begin{array}{l}\text { Adjusted HR of death } \\
\qquad(95 \% \mathrm{Cl}) \#\end{array}$ & 1 & $0.64(0.42$ to 0.97$)$ & 1 & $0.59(0.37$ to 0.93$)$ \\
\hline$P$ & & .035 & & .022 \\
\hline \multicolumn{5}{|c|}{ 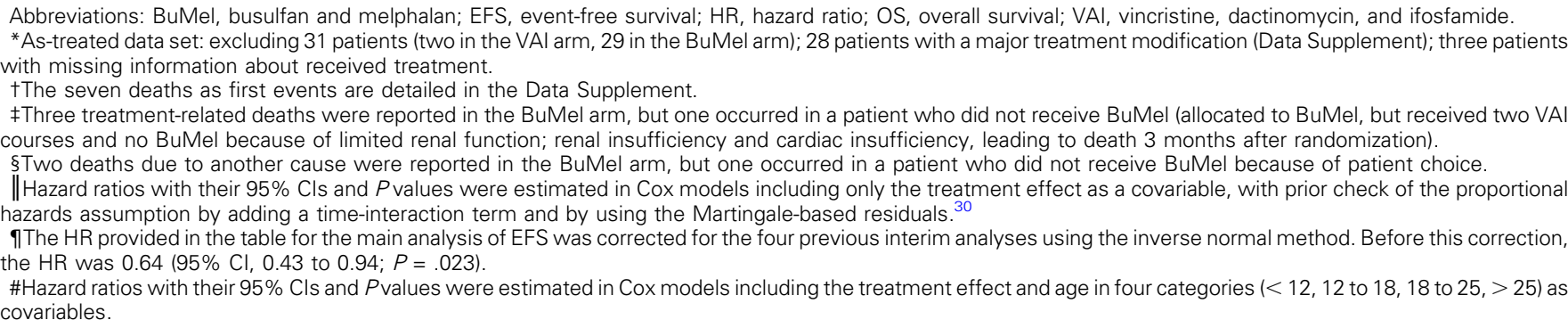 } \\
\hline
\end{tabular}

used alone to exclude patients from treatment with BuMel if all other criteria for possible benefit are fulfilled. It is also possible that there may be less benefit for older patients, although this observation may be by chance, and the test for interaction was not significant.

BuMel was chosen as HDT based on international transplant registry data ${ }^{16,18}$ and previous work by the French Society of Pediatric Oncology. ${ }^{20}$ Concerns about interaction with radiotherapy, including fatal toxicity, led to a protocol amendment after which patients requiring large-volume or high-dose radiotherapy to critical organs were excluded from randomization. ${ }^{23}$ There is little evidence to define thresholds for concurrent use of radiotherapy and busulfan. Others have reported its use after whole-lung irradiation without significant toxicity. ${ }^{36}$ There are no data to support equivalent efficacy with treosulfan, which, although closely related to busulfan, is less radiosensitizing.

We chose to compare BuMel against seven cycles of maintenance chemotherapy only. Given that the effect of HDT in this series is seen in a reduction in the incidence of subsequent metastases, which were often pulmonary, we cannot exclude that whole-lung irradiation would have similar benefits. ${ }^{37,38}$

Extrapolation of benefit to other settings in ES is to be cautioned against. A similar effect of BuMel on survival in patients presenting with pulmonary metastases was not observed when bilateral pulmonary irradiation was added to conventional 


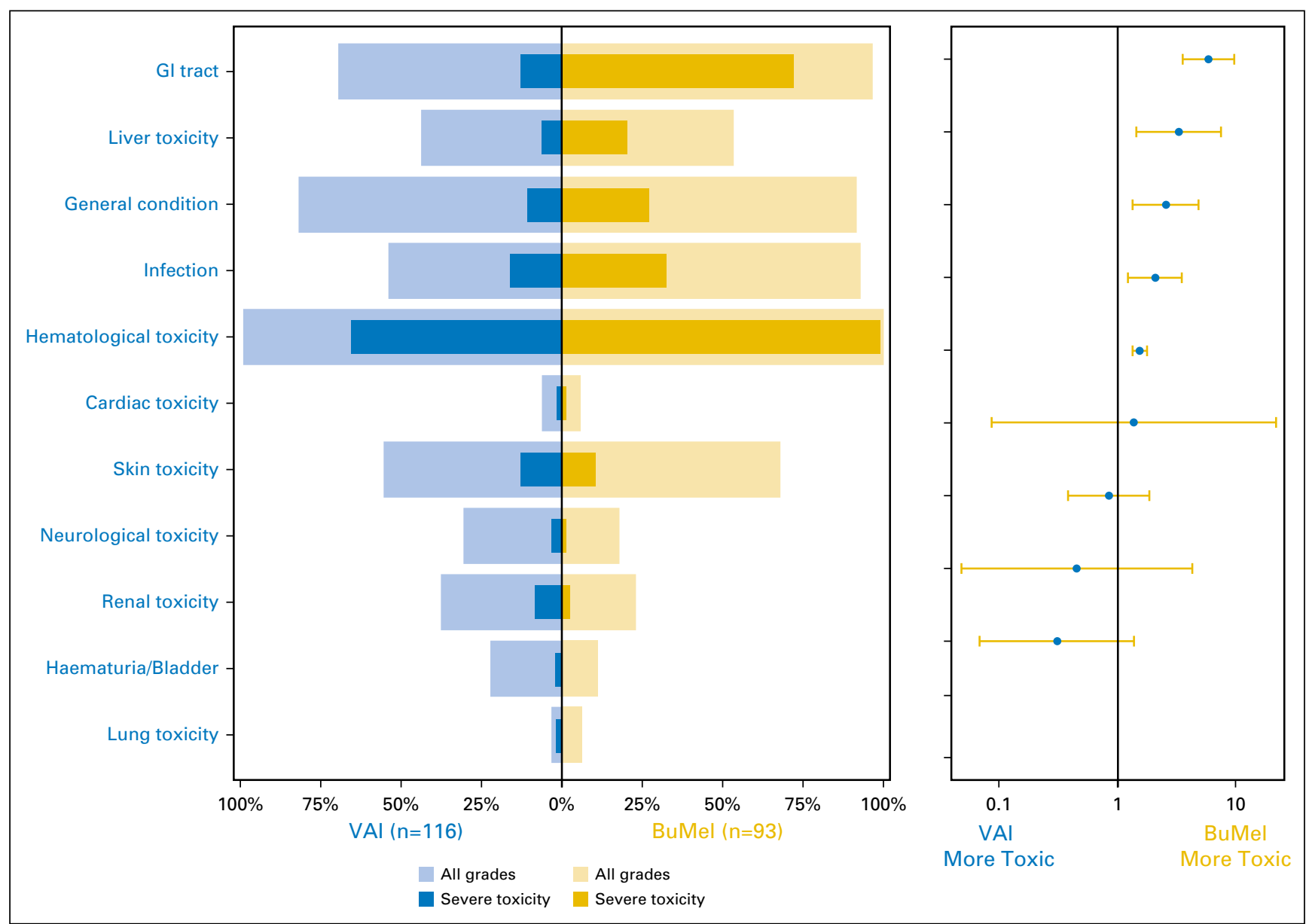

Fig 3. Adverse events. The panel on the left is a butterfly plot showing the proportion of patients experiencing an adverse event, whatever the grade (gold for busulfan and melphalan [BuMel] and blue for the vincristine, dactinomycin, and ifosfamide [VAl] arm), and a severe adverse event (dark gold for BuMel and dark blue for VAl arm) according to the randomization group. The panel on the right displays the relative risk of a severe adverse event in patients with BuMel relative to patients with VAl, with $95 \% \mathrm{Cls}$ for a $2 \times 2$ table. The acute toxicity related to chemotherapy was assessed after each course, using a list of 22 selected items from the National Cancer Institute Common Toxicity Criteria version 2.0. A modified list of items was used to evaluate toxicity after radiotherapy, using Radiation Therapy Oncology Group classification for eight types of specific toxicities. A free text area was available to document other adverse reactions. The toxicity items were then pooled by category: bladder toxicity, cardiac toxicity, Gl toxicity, general deterioration, hematologic toxicity, infection, liver toxicity, lung toxicity, neurologic toxicity (including mood alteration), renal toxicity, and skin toxicity. The respiratory tract toxicity (larynx, pharynx, salivary gland) reported after radiotherapy was pooled within the category GI toxicity because of small numbers and because they were usually associated. Details are provided in the Data Supplement. For each adverse event type, the analysis is based on the maximum grade observed over the whole maintenance treatment duration. A grade 4 hematologic toxicity and a grade $\geq 3$ nonhematologic toxicity were classified as severe toxicities. The categories of adverse event are ordered by decreasing value of the relative risk of severe toxicity. This analysis was performed on the safety set (116 VAl patients and 93 BuMel patients), excluding patients who did not receive the treatment allocated by randomization, similar to the as-treated population. The number of chemotherapy courses followed by toxicity over the whole maintenance treatment duration is detailed in the Data Supplement.

chemotherapy. ${ }^{37}$ Uncontrolled studies of HDT in patients with recurrent ES describe some patients with far superior survival than would be expected from conventionally dosed chemotherapy alone, but no randomized studies have been conducted. ${ }^{39,40}$ It is possible that different induction regimens may select different groups of patients for which the benefits of BuMel may also differ. Whether results similar to those reported here are achievable with dose-compressed vincristine, doxorubicin, cyclophosphamide/ifosfamide and etoposide is an open question. ${ }^{2}$

As expected, more patients experienced severe toxicity in the BuMel arm than in the VAI arm, mostly hematologic, digestive, and hepatic. However, these types of toxicity were transient and occurred only once after BuMel compared with repetitive hematologic toxicity with VAI courses. Two patients died as a result of BuMel toxicity, including one as a result of interaction with radiotherapy. Recommendations for the use of radiotherapy with BuMel as adopted during this study should limit this risk. Long-term toxicity from this and similar cohorts has yet to be reported.

These results are a further illustration of the value of international collaboration in rare cancers such as ES. Although the study was challenging to undertake, patients and their clinicians can now benefit from randomized evidence of the value of this treatment. Although the benefit was shown for a relatively small subgroup, the reliable demonstration of EFS and OS improvement indicates that BuMel may be considered as a standard of care for patients with localized ES fulfilling the definition of 
high-risk disease used in this trial and no contraindication to BuMel.

\section{AUTHORS' DISCLOSURES OF POTENTIAL CONFLICTS} OF INTEREST

Disclosures provided by the authors are available with this article at jco.org.

\section{AUTHOR CONTRIBUTIONS}

Conception and design: Jeremy Whelan, Marie-Cecile Le Deley, Douglas S. Hawkins, Stefan Burdach, Ruth Ladenstein, Jean Michon, Michael Paulussen, Andreas Ranft, Hendrik van den Berg, Ian Lewis, Alan Craft, Heribert Juergens

Administrative support: Marta Jimenez
Provision of study materials or patients: Uta Dirksen, Gwénaël Le Teuff, Stefan Bielack, Jean-Yves Blay, Angelika Eggert, Hans Gelderblom, Jean-Claude Gentet, Wolfgang Hartmann, Wolf-Achim Hassenpflug, Lars Hjorth, Marta Jimenez, Thomas Klingebiel, Valerie Laurence, Perrine Marec-Berard, Jean Michon, Michael Paulussen, Andreas Ranft, Hendrik van den Berg, Ian Lewis, Alan Craft

Data analysis and interpretation: Jeremy Whelan, Marie-Cecile Le Deley, Uta Dirksen, Gwénaël Le Teuff, Bernadette Brennan, Nathalie Gaspar, Douglas S. Hawkins, Susanne Amler, Sebastian Bauer, Stefan Bielack, JeanYves Blay, Stefan Burdach, Marie-Pierre Castex, Dagmar Dilloo, Hans Gelderblom, Jean-Claude Gentet, Wolfgang Hartmann, Wolf-Achim Hassenpflug, Lars Hjorth, Thomas Klingebiel, Udo Kontny, Jarmila Kruseova, Ruth Ladenstein, Valerie Laurence, Cyril Lervat, Perrine MarecBerard, Sandrine Marreaud, Bruce Morland, Michael Paulussen, Andreas Ranft, Peter Reichardt, Hendrik van den Berg, Keith Wheatley, Ian Judson, Ian Lewis, Alan Craft, Heribert Juergens, Odile Oberlin

Manuscript writing: All authors

Final approval of manuscript: All authors

Accountable for all aspects of the work: All authors

\section{REFERENCES}

1. Le Deley M-C, Paulussen M, Lewis I, et al: Cyclophosphamide compared with ifosfamide in consolidation treatment of standard-risk Ewing sarcoma: Results of the randomized noninferiority EuroEWING99-R1 trial. J Clin Oncol 32:2440-2448, 2014

2. Womer RB, West DC, Krailo MD, et al: Randomized controlled trial of interval-compressed chemotherapy for the treatment of localized Ewing sarcoma: A report from the Children's Oncology Group. J Clin Oncol 30:4148-4154, 2012 [Erratum: J Clin Oncol 33:814, 2015]

3. Paulussen M, Craft AW, Lewis I, et al: Results of the EICESS-92 Study: Two randomized trials of Ewing's sarcoma treatment-Cyclophosphamide compared with ifosfamide in standard-risk patients and assessment of benefit of etoposide added to standard treatment in high-risk patients. J Clin Oncol 26:4385-4393, 2008

4. Bacci G, Forni C, Longhi A, et al: Long-term outcome for patients with non-metastatic Ewing's sarcoma treated with adjuvant and neoadjuvant chemotherapies. 402 patients treated at Rizzoli between 1972 and 1992. Eur J Cancer40:73-83, 2004

5. Cotterill SJ, Ahrens S, Paulussen $M$, et al: Prognostic factors in Ewing's tumor of bone: Analysis of 975 patients from the European Intergroup Cooperative Ewing's Sarcoma Study Group. J Clin Oncol 18:3108-3114, 2000

6. Göbel V, Jürgens H, Etspüler G, et al: Prognostic significance of tumor volume in localized Ewing's sarcoma of bone in children and adolescents. J Cancer Res Clin Oncol 113:187-191, 1987

7. Marina N, Granowetter L, Grier HE, et al: Age, tumor characteristics, and treatment regimen as event predictors in Ewing: A Children's Oncology Group report. Sarcoma 2015:927123, 2015

8. Oberlin O, Deley MC, Bui BN, et al: Prognostic factors in localized Ewing's tumours and peripheral neuroectodermal tumours: The third study of the French Society of Paediatric Oncology (EW88 study). Br J Cancer 85:1646-1654, 2001

9. Paulussen M, Ahrens S, Dunst J, et al: Localized Ewing tumor of bone: Final results of the cooperative Ewing's Sarcoma Study CESS 86. J Clin Oncol 19:1818-1829, 2001

10. Bacci G, Ferrari S, Bertoni F, et al: Prognostic factors in nonmetastatic Ewing's sarcoma of bone treated with adjuvant chemotherapy: Analysis of 359 patients at the Istituto Ortopedico Rizzoli. J Clin Oncol 18:4-11, 2000

11. Le Deley MC, Ahrens S, Paulussen M, et al: Histological response is the main prognostic factor of survival in localised Ewing tumor treated with chemotherapy alone before surgery. International Society of Pediatric Oncology (SIOP). Brisbane. Pediatr Blood Cancer 85:1646-1654, 2001

12. Cornbleet MA, Corringham RE, Prentice HG, et al: Treatment of Ewing's sarcoma with high-dose melphalan and autologous bone marrow transplantation. Cancer Treat Rep 65:241-244, 1981

13. Hartmann O, Benhamou E, Beaujean F, et al: High-dose busulfan and cyclophosphamide with autologous bone marrow transplantation support in advanced malignancies in children: A phase II study. J Clin Oncol 4:1804-1810, 1986

14. Hartmann O, Oberlin O, Beaujean F, et al: Role of high-dose chemotherapy followed by bone marrow autograft in the treatment of metastatic Ewing's sarcoma in children [in French]. Bull Cancer 77:181 187, 1990

15. Burdach $S$, Jürgens $H$, Peters $C$, et al: Myeloablative radiochemotherapy and hematopoietic stem-cell rescue in poor-prognosis Ewing's sarcoma. J Clin Oncol 11:1482-1488, 1993

16. Ladenstein $R$, Lasset $C$, Pinkerton $R$, et al: Impact of megatherapy in children with high-risk Ewing's tumours in complete remission: A report from the EBMT Solid Tumour Registry. Bone Marrow Transplant 15:697-705, 1995 [Erratum: Bone Marrow Transplant 15:697-705, 1995]

17. Atra A, Whelan JS, Calvagna V, et al: Highdose busulphan/melphalan with autologous stem cell rescue in Ewing's sarcoma. Bone Marrow Transplant 20:843-846, 1997

18. Ladenstein $R$, Hartmann $O$, Pinkerton $R$, et al: A multivariate and matched pair analysis on high-risk Ewing tumor (ET) patients treated by megatherapy (MGT) and stem cell reinfusion (SCR) in Europe. Proc Am Soc Clin Oncol 18:555, 1999 (abstr)

19. Ferrari $S$, Sundby Hall $K$, Luksch $R$, et al: Nonmetastatic Ewing family tumors: High-dose chemotherapy with stem cell rescue in poor responder patients. Results of the Italian Sarcoma Group/Scandinavian Sarcoma Group III protocol. Ann Oncol 22:1221-1227, 2011

20. Gaspar N, Rey A, Bérard PM, et al: Risk adapted chemotherapy for localised Ewing's sarcoma of bone:
The French EW93 study. Eur J Cancer 48:1376-1385, 2012

21. Juergens $C$, Weston $C$, Lewis I, et al: Safety assessment of intensive induction with vincristine, ifosfamide, doxorubicin, and etoposide (VIDE) in the treatment of Ewing tumors in the EUROE.W.I.N.G. 99 clinical trial. Pediatr Blood Cancer 47: 22-29, 2006

22. Ladenstein $R$, Pötschger $U$, Le Deley MC, et al: Primary disseminated multifocal Ewing sarcoma: Results of the Euro-EWING 99 trial. J Clin Oncol 28:3284-3291, 2010

23. Toxicity of high-dose chemotherapy (busulfanmelphalan) followed by radiation therapy (RT) in Ewing's axial tumours: Results of the French study. in International Society of Paediatric Oncology (SIOP). Pediatr Blood Cancer 49:555, 2007 (abstr)

24. Strauss SJ, McTiernan $A$, Driver $D$, et al: Single center experience of a new intensive induction therapy for Ewing's family of tumors: Feasibility, toxicity, and stem cell mobilization properties. J Clin Oncol 21: 2974-2981, 2003

25. Bearman $\mathrm{SI}$, Anderson $\mathrm{GL}$, Mori $\mathrm{M}$, et al: Venoocclusive disease of the liver: Development of a model for predicting fatal outcome after marrow transplantation. J Clin Oncol 11:1729-1736, 1993

26. RTOG Foundation: RTOG/EORTC Late Radiation Morbidity Scoring Schema. https://www.rtog. org/ResearchAssociates/AdverseEventReporting/ RTOGEORTCLateRadiationMorbidityScoringSchema. aspx

27. Freedman LS: Tables of the number of patients required in clinical trials using the logrank test. Stat Med 1:121-129, 1982

28. Lan KG, DeMets DL: Discrete sequential boundaries for clinical trials. Biometrika 70:659-663, 1983

29. O'Brien PC, Fleming TR: A multiple testing procedure for clinical trials. Biometrics 35:549-556, 1979

30. McTiernan AM, Cassoni AM, Driver $D$, et al: Improving outcomes after relapse in Ewing's sarcoma: Analysis of 114 patients from a single institution. Sarcoma 2006:83548, 2006

31. Wassmer G: Planning and analyzing adaptive group sequential survival trials. Biom J 48:714-729, 2006

32. Kalbfleisch J, Prentice R: The Statistical Analysis of Failure Time Data (ed 2). New York, NY, Wiley, 2002 
33. Fine JP, Gray R: A proportional hazards model for the subdistribution of a competing risk. J Am Stat Assoc 94:496-509, 1999

34. Cherny NI, Sullivan R, Dafni U, et al: A standardised, generic, validated approach to stratify the magnitude of clinical benefit that can be anticipated from anti-cancer therapies: The European Society for Medical Oncology Magnitude of Clinical Benefit Scale (ESMO-MCBS). Ann Oncol 26:1547-1573, 2015

35. Gaspar N, Hawkins DS, Dirksen U, et al: Ewing sarcoma: Current management and future approaches through collaboration. J Clin Oncol 33:3036-3046, 2015
36. Luksch $R$, Tienghi $A$, Hall KS, et al: Primary metastatic Ewing's family tumors: Results of the Italian Sarcoma Group and Scandinavian Sarcoma Group ISG/SSG IV Study including myeloablative chemotherapy and total-lung irradiation. Ann Oncol 23:2970-2976, 2012

37. Whelan JS, Burcombe RJ, Janinis J, et al: A systematic review of the role of pulmonary irradiation in the management of primary bone tumours. Ann Oncol 13:23-30, 2002

38. Razek A, Perez CA, Tefft M, et al: Intergroup Ewing's Sarcoma Study: Local control related to radiation dose, volume, and site of primary lesion in Ewing's sarcoma. Cancer 46:516-521, 1980

39. Barker LM, Pendergrass TW, Sanders JE, et al: Survival after recurrence of Ewing's sarcoma family of tumors. J Clin Oncol 23:4354-4362, 2005

40. Rasper M, Jabar S, Ranft A, et al: The value of high-dose chemotherapy in patients with first relapsed Ewing sarcoma. Pediatr Blood Cancer 61: 1382-1386, 2014

41. Lin DY, Wei L-J, Ying Z: Checking the Cox model with cumulative sums of martingale-based residuals. Biometrika 80:557-572, 1993

\section{Affiliations}

Jeremy Whelan, University College Hospital; Ian Judson, Institute of Cancer Research, London; Bernadette Brennan, Royal Manchester Children's Hospital, Manchester; Bruce Morland, Birmingham Children's Hospital; Keith Wheatley, University of Birmingham, Birmingham; Ian Lewis, Leeds Community Healthcare National Health Service Trust, Leeds; Alan Craft, Newcastle University, Newcastle upon Tyne, United Kingdom; Marie-Cecile Le Deley and Cyril Lervat, Centre Oscar Lambret, Lille; Gwénaël Le Teuff, Nathalie Gaspar, and Odile Oberlin, Institut Gustave Roussy, Villejuif; Jean-Yves Blay, Centre Léon Bérard; Perrine MarecBerard, Institute of Pediatric Onco-Haematology, Lyon; Marie-Pierre Castex, Centre Hospitalier Universitaire de Toulouse, Toulouse; Jean-Claude Gentet, Centre Hospitalier Universitaire La Timone, Marseille; Marta Jimenez, Unicancer; Valerie Laurence and Jean Michon, Institut Curie, Paris; France; Uta Dirksen, Sebastian Bauer, Andreas Ranft, University Hospital Essen, Essen; Susanne Amler, Institut für Biometrie und Klinische Forschung; Wolfgang Hartmann and Heribert Juergens, Universitätsklinikum, Münster, Münster; Stefan Bielack, Klinikum Stuttgart, Stuttgart; Stefan Burdach, Comprehensive Cancer Center, München; Dagmar Dilloo, UniversityClinic Bonn, Bonn; Angelika Eggert, Charité University; Peter Reichardt, HELIOS Klinikum Berlin-Buch, Berlin; Wolf-Achim Hassenpflug, University Medical Center Hamburg-Eppendorf, Hamburg; Thomas Klingebiel, Childrens University Hospital, Frankfurt; Udo Kontny, University Medical Center Aachen, Aachen; Michael Paulussen, Children's and Adolescents' Hospital, Datteln; Germany; Douglas S. Hawkins, Seattle Children's Hospital, Seattle, WA; Hans Gelderblom, Leiden University Medical Center, Leiden; Hendrik van den Berg, University of Amsterdam, Amsterdam, the Netherlands; Lars Hjorth, Skane University Hospital, Lund, Sweden; Jarmila Kruseova, Faculty Hospital Motol Prague, Prague, Czech Republic; Ruth Ladenstein, St Anna Children's Hospital and Children's Cancer Research Institute, Vienna, Austria; Sandrine Marreaud, European Organisation for Research and Treatment of Cancer, Brussels, Belgium

\section{Support}

Euro-E.W.I.N.G.99 is an academic clinical trial funded through multiple national and international government agencies and cancer charities: FP7-EURO EWING Consortium; Germany: Deutsche Krebshilfe (Grants No. 70-2551-Jue3 and 108128), and Bundesministerium für Bildung und Forschung (Grants No. BMBF 01GM0869 and BMBF/Era-Net 01KT1310); France: Association Enfants et Santé, Société Française de Lutte Contre les Cancers et les Leucémies de l'Enfant et de l'Adolescent, Unicancer; United Kingdom: Cancer Research UK (Grant No. CRUK/02/014), National Institute for Health Research University College London Hospitals Biomedical Research Centre.

\section{Prior Presentation}

Presented at the ASCO Annual Meeting, Chicago, IL, June 3 to 7, 2016; and the Connective Tissue Oncology Society Annual Meeting, Lisbon, Portugal, November 9 to 12, 2006. 
High-Dose Chemotherapy and Blood Autologous Stem-Cell Rescue Compared With Standard Chemotherapy in Localized High-Risk Ewing Sarcoma: Results of Euro-E.W.I.N.G.99 and Ewing-2008

The following represents disclosure information provided by authors of this manuscript. All relationships are considered compensated. Relationships are self-held unless noted. I = Immediate Family Member, Inst = My Institution. Relationships may not relate to the subject matter of this manuscript. For more information about ASCO's conflict of interest policy, please refer to www.asco.org/rwc or ascopubs.org/jco/site/ifc.

Jeremy Whelan

No relationship to disclose

Marie-Cecile Le Deley

No relationship to disclose

Uta Dirksen

Consulting or Advisory Role: Eli Lilly (Inst)

Travel, Accommodations, Expenses: Jazz Pharmaceuticals

Gwénaël Le Teuff

No relationship to disclose

Bernadette Brennan

Travel, Accommodations, Expenses: Jazz Pharmaceuticals

Nathalie Gaspar

Travel, Accommodations, Expenses: EISAI

Douglas S. Hawkins

Travel, Accommodations, Expenses: Loxo, Bayer, Bristol-Myers Squibb, Celgene

Susanne Amler

No relationship to disclose

\section{Sebastian Bauer}

Honoraria: Novartis, Pfizer, Bayer, Pharmamar, GlaxoSmithKline

Consulting or Advisory Role: Blueprint Medicines, Bayer, Eli Lilly, Deciphera, Nanobiotix

Research Funding: Blueprint Medicines, Novartis, Incyte (Inst)

Travel, Accommodations, Expenses: Pharmamar

Stefan Bielack

Consulting or Advisory Role: Clinigen Group, Bayer, Eli Lilly, Pfizer, Novartis, Isofol Medical, Sensorion

Research Funding: Janssen-Cilag (Inst), Amgen (Inst), EISAI (Inst), Loxo

Jean-Yves Blay

No relationship to disclose

Stefan Burdach

Stock or Other Ownership: PDLI

Marie-Pierre Castex

No relationship to disclose

Dagmar Dilloo

Stock or Other Ownership: Pfizer, Amgen (I), Johnson \& Johnson, Merck (I)

Angelika Eggert

No relationship to disclose

Hans Gelderblom

No relationship to disclose

Jean-Claude Gentet

No relationship to disclose

\section{Wolfgang Hartmann}

Travel, Accommodations, Expenses: Menarini

Wolf-Achim Hassenpflug

Consulting or Advisory Role: Shire, CSL Behring, SOBI

Travel, Accommodations, Expenses: Shire, Novo Nordisk

Lars Hjorth

Stock or Other Ownership: Bioinvent

Marta Jimenez

No relationship to disclose

Thomas Klingebiel

No relationship to disclose

Udo Kontny

Consulting or Advisory Role: Eisai

Jarmila Kruseova

No relationship to disclose

Ruth Ladenstein

Honoraria: Apeiron Biologics, Boehringer Ingelheim, EUSA Pharma Consulting or Advisory Role: Apeiron Biologics, Boehringer Ingelheim, EUSA Pharma (Inst)

Research Funding; Apeiron Biologics (Inst), EUSA Pharma (Inst)

Patents, Royalties, Other Intellectual Property: Apeiron Biologics (Inst) Expert Testimony: Apeiron Biologics, EUSA Pharma

Travel, Accommodations, Expenses: Apeiron Biologics, EUSA Pharma

Valerie Laurence

No relationship to disclose

Cyril Lervat

Travel, Accommodations, Expenses: Chugai Pharma

Perrine Marec-Berard

No relationship to disclose

Sandrine Marreaud

No relationship to disclose

Jean Michon

Travel, Accommodations, Expenses: Bristol-Myers Squibb

Bruce Morland

Consulting or Advisory Role: Bayer. Clinigen Group

Michael Paulussen

No relationship to disclose

Andreas Ranft

No relationship to disclose 
Peter Reichardt

Honoraria: Novartis, Pfizer, Bayer, PharmaMar, Eli Lilly, GSK, Amgen Consulting or Advisory Role: GSK, Novartis, Clinigen Group, Eli Lilly, Merck, Bayer, Roche, BMS

Research Funding: Novartis (Inst)

Hendrik van den Berg

No relationship to disclose

Keith Wheatley

Research Funding: Novartis (Inst)

Ian Judson

Honoraria: Eli Lilly

Consulting or Advisory Role: Eli Lilly

Research Funding: AstraZeneca (Inst)

Patents, Royalties, Other Intellectual Property: Rewards to inventors relating to patent for abiraterone acetate

Travel, Accommodations, Expenses: Eli Lilly
Ian Lewis

No relationship to disclose

\section{Alan Craft}

No relationship to disclose

Heribert Juergens

No relationship to disclose

Odile Oberlin

No relationship to disclose 


\section{Acknowledgment}

We are indebted to all the patients and parents who agreed to participate in this study; Carolyn Douglas, Sue Ablett, Paul Donachie, Children's Cancer and Leukaemia Group Data Centre, Leicester, United Kingdom; Davina Scott, Jennifer Anderton, Nicola Fenwick, Keith Wheatley, Veronica Moroz, Cancer Research UK Clinical Trials Unit, University of Birmingham, United Kingdom; Susanne Ahrens, Martina Blankschän, Gabriele Braun-Munzinger, Susanne Jabar, Andreas Ranft, Gesellschaft für Pädiatrische Onkologie und Hämatologie data center, Münster, Germany; Eva Sorz, Austrian-Gesellschaft für Pädiatrische Onkologie und Hämatologie data center, Vienna, Austria; Anthony Mangin, Jean-François Leforestier, Yulia Belikova, Noel Ny Tovo, Zakia Idir, Fatima Bizeul, Julien Marandet, Muriel Wartelle, Nathalie Cozic, Institut Gustave Roussy, Villejuif; Marta Jimenez, Céline Mahier Aït Oukhatar, Naïma Bonnet, Jessy Delaye, Jean Genève, Unicancer, Paris, France; Christine Olungu, Anne Kirkpatrick, Saskia Litiere, Sandrine Marreaud, European Organization for Research and Treatment of Cancer data center, Brussels, Belgium, for data management and study coordination assistance; Robert Souhami, Paul Meyers, and Abdel Babiker for participating in the Independent Data Monitoring Committee; and all investigators who participated in the trial.

\section{Appendix}

All investigators who participated in the trial:

From Austria: Ch. Urban, University Children's Hospital, Graz; B. Meister and F.M. Fink, University Children's Hospital, Innsbruck; R. Kerbl, Leoben Clinical Centre, Children's Hospital Leoben; O. Stollinger, Children's Hospital Barmherzige Schwestern, Linz; K. Schmitt and G. Ebetsberger, Linz Clinical Centre, Children's Hospital, Linz; N. Jones, University Hospital, Salzburg, R. Ladenstein and H. Gadner, St Anna Children's Hospital, Wien; B. Ausserer, Children`s Hospital, Dornbirn;

From Belgium: P. Maes, AZM Children's Cancer Centre, Antwerpen; B. Brichard, University Children's Hospital, Brussels; F. Mazzeo, University Hospital, Clinical Oncology, Brussels; T. Gil, Hôpitaux universitaires Bordet-Erasme, Brussels; C. Dhooge, Universitair Ziekenhuis, Gent; J.B. Vermorken, Universitair Ziekenhuis, Antwerpen; A. Klein, Hôpital Universitaire des Enfants Reine Fabiola, Brussels;

From Czech Republic: J. Kruseova, University Hospital Motol, Prague;

From Denmark: A. Krarup-Hansen, Herlev Hospital-University, Copenhagen; O. Nielsen, Aarhus University Hospital, Aarhus; From Ireland: M. Capra, Our Lady’s Children's Hospital, Dublin;

From Finland: J. Kanerva, Pediatric Oncology, Helsinki University Children's Hospital, Helsinki, Finland;

From France: C. Devoldere, University Hospital, Amiens; I. Pellier, University Hospital, Angers; O. Collard, Institut de Cancerologie de l'Ouest, Saint Priest en Jarez; P. Soulie, Centre Paul Papin, Angers; E. Plouvier, University Hospital, Besançon; C. Vérité, University Hospital, Bordeaux; B. Bui N’guyen, Institut Bergonié, Bordeaux; G. Dabouis, University Hospital, Nantes; F. Aubier, Hôpital d'enfants Margency, Margency; O. Minckes, University Hospital, Caen; C. Delcambre, Centre François Baclesse, Caen; J.O. Bay, Centre Jean Perrin, Clermont-Ferrand; J. Kanold, University Hospital, Clermont-Ferrand; E. Colomb, University Hospital, Dijon; N. Isambert, Centre Jean François Leclerc, Dijon; D. Plantaz, University Hospital, Grenoble; A.S Defachelles, Centre Oscar Lambret, Lille; C. Piguet, University Hospital, Limoges; P. Marec-Bérard, Centre Léon Bérard, Lyon; J.Y. Blay, Centre Léon-Bérard, Lyon; J.C. Gentet, University Hospital, Marseille; F. Duffaud, University Hospital, Marseille; F. Bertucci, Institut Paoli Calmettes, Marseille; J.P Lotz, Hôpital Tenon, Paris; L. Saumet, University Hospital, Montpellier; C. Schmitt, University Hospital, Nancy; M. Rios, Centre Alexis Vautrin, D. Cupissol, Institut du Cancer de Montpellier, Val d'Aurelle, Montpellier; Nancy; N. Corradini, University Hospital, Nantes; F. Rolland, Centre René Gauducheau, Nantes; A. Deville, University Hospital, Nice; A. Thyss, Centre Antoine Lacassagne, Nice; J. Michon, Institut Curie, Paris; M.D. Tabone, Trousseau University Hospital, Paris; V. Laurence, Institut Curie, Paris; F. Millot, University Hospital, Poitiers; S. Gorde GrosJean, University Hospital, Reims; S. Taque, University Hospital, Rennes; J.P. Vannier, University Hospital, Rouen; C. Guillemet, Centre Henri Becquerel, Rouen; L. Chauvenet, Hotel Dieu, Paris; E. Brain, Centre René Huguenin, St Cloud; C. Berger, University Hospital, St Etienne; P. Lutz, University Hospital, Strasbourg; M.P. Castex, University Hospital, Toulouse; H. Roche, Institut Claudius Regaud, Toulouse; O. Lejars, University Hospital, Tours; C. Linassier, University Hospital, Tours; O. Oberlin, Institut Gustave Roussy, Villejuif; N. Gaspar, Institut Gustave Roussy, Villejuif; A. Le Cesne, Institut Gustave Roussy, Villejuif;

From Germany (EORTC): S. Bauer, P. Ebeling, and M. Flasshove, Essen University Hospital, Essen; J.T. Hartmann, Eberhard Karls University, Tuebingen; P. Reichardt, Charité Universitaetsmedizin, Campus Berlin- Bush, Berlin

From Germany (GPOH): R. Mertens, U. Kontny, University Children's Hospital, Aachen; R. Osieka, University Hospital, Medical Oncology, Aachen; A. Gnekow, Augsburg Clinical Centre, Children's Hospital, Augsburg; G. Schlimok, Medical Oncology, Augsburg Clinical Centre, Augsburg; G. Henze, P. Hundsdörfer, Charité Virchow Clinical Centre, Children's Hospital, Berlin; P. 
Thuss-Patience, A. Kunitz, Charité Virchow Clinical Centre, Berlin; L. Wickmann, L. Schweigerer, Berlin-Buch Children's Hospital, Berlin; P. Reichardt, Medical Oncology, Berlin-Buch Clinical Centre, Berlin; K. Possinger, Medical Oncology, Charité Central Campus, Berlin; J. Potenberg, Ev. Waldkrankenhaus, Berlin; P. Reichardt, Charité Universitaetsmedizin, Campus Berlin-Buch, Berlin; N. Jorch, Ev. Children's Hospital Bielefeld; U. Krümpelmann, Medical Oncology Ev. Hospital, Bielefeld; H. Weh, Medical Oncology, Franziskus Hospital, Bielefeld; J. Baier, Medical Oncology, St Josef's Hospital, Bochum; W. Schmiegel, Medical Oncology, Ruhr-University Hospital, Bochum; U. Bode, D. Dilloo, University Children's Hospital, Bonn; I.G.M. Schmidt-Wolf, V. Janzen, Medical Oncology I, University Hospital Bonn; J. Nolting, University Hospital, Medical Oncology III, Bonn; W. Eberl, Children's Hospital, Braunschweig; B. Wörmann, Medical Oncology, City Hospital, Braunschweig; W. Hoffmann, Radiology and Radiotherapy, City Hospital, Braunschweig; Th. Wolff, J. Kullmer, Ev. Diakonie Hospital, Bremen; A. Pekrun, Bremen Mitte Children's Hospital, Bremen; A. Hofmann, Children's Hospital, Chemnitz; G. Geißler, Internal Medicine III, Chemnitz; E. Hohlfeld; CarlThiem-Hospital, Cottbus; W. Andler, T. Wiesel, Children's Hospital, Datteln; D. Schneider, B. Bernbeck, Children's Hospital, Dortmund; I. Lauterbach, M. Suttorp, University Children's Hospital, Dresden; S. Richter, G. Ehninger, University Hospital Dresden; P. Zickler, Children's Hospital, Duisburg; U. Göbel, A. Borkhardt, University Children's Hospital, Düsseldorf; J.-N. Machatschek, Medical Oncology, University Hospital, Düsseldorf; A. Lemmer, A. Sauerbrey, Children's Hospital, Erfurt; W. Holter, M. Metzler, University Children's Hospital, Erlangen; N. Meidenbauer, University Hospital, Erlangen; S. Seeber, S. Bauer, P. Ebeling, and M. Flasshove, University Hospital, Essen; A. Eggert, G. Fleischhack, University Children's Hospital, Essen; T. Klingebiel, University Children's Hospital Frankfurt, M. Ahrens University Hospital Frankfurt; C. Niemeyer, J. Rößler, University Children's Hospital, Freiburg; J. Heinz, Medical Oncology, University Hospital, Freiburg; A. Reiter, W. Wössmann University Children's Hospital, Giessen; M. Rummel, W. Blau, Medical Oncology, University Hospital, Giessen; V. Runde, Goch Clinical Centre, Goch; M. Lakomek, C. Kramm University Children's Hospital, Göttingen; L. Trümper, D. Hertramph, Medical Oncology, University Hospital, Göttingen; J. Beck, H. Lode University Children’s Hospital, Greifswald; G. Dölken, Medical Oncology, University Hospital, Greifswald; H.-W. Lindemann, Hagen Clinical Centre, Hagen; G. Günther, D. Körholz, T. Bernig, University Children's Hospital, Halle; H.-J. Schmoll, Medical Oncology, University Hospital, Halle; R. Schneppenheim, W.A. Hassenpflug, UKE University Children's Hospital, Hamburg; D.K. Hossfeld, C. Bokemeyer, Medical Oncology, UKE University Hospital, Hamburg; W. Alberti, Radiology and Radiotherapy, UKE University Hospital, Hamburg; H. Keles, Medical Oncology, Asklepios Hospital Altona, Hamburg; N. Schmitz, Haematology, Asklepios Hospital St Georg, Hamburg; N. Brüllke, Medical Oncology, Asklepios Hospital Barmbek, Hamburg; H. Schmidt, Internal Medicine, Regional Hospital, Hameln; C. Dürk, Medical Oncology, St Marien Hospital, Hamm; K. Welte, C. Klein, B. Maecker-Kohlhoff, Pediatric Oncology, Hannover Medical School, Hannover; Ch. Reuter, Medical Oncology, Hannover Medical School, Hannover; H. Kirchner, Medical Oncology III, Siloah Hospital, Hannover; A. Kulozik, W. Behnisch, University Children's Hospital, Heidelberg; G. Egerer, Medical Oncology, University Hospital, Heidelberg; Ewerbeck, Orthopedic, University Hospital, Heidelberg; M. Thomas, Medical Oncology, Thorax Hospital, Heidelberg; J. Cyran, Clinical Centre, Heilbronn; Kachel, Pediatrics, SLK Hospital, Heilbronn; U. Martens, Pediatric, Haematology, SLK Hospital Heilbronn; Ch. Tautz, General Hospital, Herdecke; D. Strumberg, St Marien Hospital, Herne; W. Freier, Oncology Practice, Hildesheim; U. Kaiser, Medical Oncology II, St Bernward, Hildesheim; N. Graf, University Children's Hospital, Homburg; M. Pfreundschuh, Medical Oncology, University Hospital, Homburg; F. Zintel, B. Gruhn, University Children's Hospital, Jena; E. Eigendorff, University Hospital, Jena; H. Link, Medical Oncology, Westpfalz Hospital, Kaiserslautern; R. Germann, A. Leipold, Children's Hospital, Karlsruhe; Th. Fischer, M. Bentz, Medical Oncology, Karlsruhe Clinical Centre, Karlsruhe; J. Mezges, Medical Oncology, St Vincentius Hospital, Karlsruhe; H. Wehinger, M. Nathrath, Children's Hospital, Kassel; M. Wolf, Medical Oncology, Kassel Hospital, Kassel; H. Meye, Radiotherapy, Kassel Hospital, Kassel; Prümmer, Internal Medicine III, Kempten Ober-Allgäu Hospital, Kempten; M. Schrappe, A. Claviez, University Children's Hospital, Kiel; M. Lamprecht, Medical Oncology II, University Hospital, Kiel; H. Nolte, Kemperhof Clinical Centre, Koblenz; M. Rister, M. Jakob, Kemperhof Koblenz, Koblenz; F. Berthold, T. Simon, University Children's Hospital, Cologne; V. Diehl, J. Wolf, Medical Oncology, University Hospital, Cologne; W. Sternschulte, A. Prokop, Children's Hospital, Cologne; E. Stoelben, Pulmonary Hospital, Cologne; S. Voelpel, T. Imschweiler, Children's Hospital, Krefeld; T. Frieling, Medical Oncology, Krefeld Clinical Centre, Krefeld; J. Moessner, D. Niederwiese, Medical Oncology, University Hospital, Leipzig; U. Bierbach, H. Christiansen, University Children’s Hospital, Leipzig; J. Bennek, Pediatric Surgery, University Hospital, Leipzig; L. Mantovani, Medical Oncology, St Georg Hospital, Leipzig; D. Selle, St Annastift Children's Hospital, Ludwigshafen; P. Bucsky, T. Langer, University Children's Hospital, Lübeck; H. Bartels, Medical Oncology, Clinical Centre Lübeck South, Lübeck; Th. Wagner, Medical Oncology I, University Hospital, Lübeck; G. Heil, Medical Oncology, Reginal Hospital, Lüdenscheid; M. Mohren, Th. Fischer, E. Schalk, Medical Oncology, University Hospital, Magdeburg; U. Kluba, P. Vorwerk, University Children's Hospital, Magdeburg; P. Gutjahr, M. Dittrich, J. Faber, University Children's Hospital, Mainz; H.-J. Beck, Medical Oncology III, University Hospital, Mainz; S. Reiter, B. Kasper, Medical Oncology III, University Hospital, Mannheim; 
M. Dürken, University Children's Hospital, Mannheim; A. Neubauer, J. Beyer, Medical Oncology, University Hospital, Marburg; B. Schütz, H. Christiansen, University Children's Hospital, Marburg; B. Erdlenbruch, Pediatrics Johannes Wesling Hospital, Minden; M. Griesshammer, Medical Oncology, Johannes Wesling Hospital, Minden; Reis, Medical Oncology, St,. Franziskus Hospital, Mönchengladbach; S. Burdach, A. Wawer, TU Technical University (TU) Clinical Centre, Children's Hospital, München; I. Schmid, Ludwig-Maximilians-University (LMU) Children's Hospital, Munich; C. Meyer zum Büschenfelde, C. Peschel, S. Lorenzen, Medical Oncology, TU Clinical Centre, Munich; B. Emmerich, M. Schlemmer, F. Oduncu, R. Issels, Medical Oncology, LMU Clinical Centre, Munich; H. Jürgens, University Children’s Hospital, Münster; W. Berdel, A. Kerkhoff, Medical Oncology, University Hospital, Münster; H. Held, Medical Oncology, Clinical Centre, Neumünster; G. Hofmann-Wackersreuther, W. Scheurlen, M. Augustin, Medical Oncology, Clinical Centre, Nürnberg; H. Müller, Children’s Hospital, Oldenburg; C.-H. Köhne, D. Krämer, Medical Oncology, Oldenburg Hospital, Oldenburg; A. Rickers, Pediatrics, Marienhospital, Osnabrück; T. Wolff, Medical Oncology, St Josef Hospital, Paderborn; U. Loss, Internal Medicine, Knappschaftshorpital, Recklinghausen; O. Peters, St Hedwig Children's Hospital, Regensburg; R. Andreesen, S. Krause, M. Grube, Medical Oncology, University Hospital, Regensburg; Kreuser, Medical Oncology, Barmherzige Brüder Hospital, Regensburg; S. Corbacioglu, University Children's Hospital, Regensburg; C.-F. Classen, University Children's Hospital, Rostock; M. Freund, Medical Oncology, University Hospital Rostock; J. Potratz, F. Heits, Medical Oncology, Rotenburg Clinical Centre, Rotenburg; R. Geib-König, Winterberg Clinical Centre, Children’s Hospital, Saarbrücken; J. Weis, Radiology and Radiotherapy, Saarbrcken Hospital, Saarbrücken; M. Kasbohm, Helios Clinical Centre, Children's Hospital, Schwerin; D. Hähling, Medical Oncology, Helios Hospital, Schwerin; D. Bürger, R. Burghard, Deutsches Rotes Kreuz Children's Hospital, Siegen; R. Dickerhoff, H. Reinhard, Asklepios Clinical Centre, Children's Hospital, St Augustin; S. Bielack, K. Apel, S. Simon-Klingenstein, Stuttgart Cancer Center, Pediatrics 5 (Oncology, Hematology, Immunology), Klinikum Stuttgart - Olgahospital, Stuttgart; H.G. Mergenthaler, G. Illerhaus, Stuttgart Cancer Center, Medical Oncology, Klinikum Stuttgart Katharinenhospital, Stuttgart; C. Denzlinger, Internal Medicine III, Marienhospital, Stuttgart; I. Feddersen, S. Weis, Rauh Mutterhaus der Borromäerinnen, Children's Hospital, Trier; M.R. Clemens, Hospital “Barmherzige Brüder”, Trier; Waladkhani, Medical Oncology I, Mutterhaus der Borromäerinnen, Trier; H. Kirchen, Medical Oncology, Barmherzige Brüder Hospital, Trier; R. Handgretinger, M. Ebinger, University Children's Hospital, Tübingen; Brossart, J.T. Hartmann, H.-G. Kopp, Eberhard Karls Universitaet, Tuebingen; ; K.-M. Debatin, University Children's Hospital, Ulm; Döhner, R. Mayer-Steinacker, University Cancer Centre, Ulm; M. Müller, A. Schoengen, Internal Medicine I, Bundeswehrkrankenhaus, Ulm; St Brettner, Medical Oncology, Regional Hospital, Waldbröhl; N. Frickhofen, Internal Medicine III, Dr.-Horst-Schmidt-Hospital, Wiebaden; Dohrn, Pediatrics, HELIOS Hospital, Wuppertal; M. Sandmann, Medical Oncology, St Antonius Hospital, Wuppertal; P. Schlegel, University Children's Hospital, Würzburg;

From Hong Kong: V. Lee and K-W Chik, Prince of Wales Hospital, The Chinese University of Hong Kong, Hong Kong;

From Hungary: P. Hauser, Semmelweis University Children's Hospital, Budapest, Hungary;

From the Netherlands: H. van den Berg, AMC Emma Children's Hospital/Academic Medical Centre, Amsterdam; S. Rodenhuis, The Netherlands Cancer Institute-Antoni Van Leeuwenhoekziekenhuis, Amsterdam; A.J. Gelderblom, J. Anninga, Leiden University Medical Centre, Cancer Centre, Leiden; P. Hoogerbrugge and JPM. Bökkerink, UMC St Radboud, Nijmegen; R. Pieters, Sophia Children's Hospital - Erasmus Medical Centre, Rotterdam;

From New Zealand: R, Corbett, Christchurch Hospital, Christchurch

From Sweden: G. Österlundh, Queen Silvia’s Children's Hospital, Sahlgrenska Hospital, Gothenburg; M. Behrendtz and B.-M. Holmqvist, Department of pediatrics, Linköping University Hospital, Linköping; L. Hjorth, Children’s Hospital, Skåne University Hospital, Lund; C. Petersen and Å. Jakobson, Astrid Lindgren’s Children’s Hospital, Karolinska Hospital, Stockholm; U. Hjalmars, Department of pediatrics, Umeå University Hospital, Umeå; G. Ljungman, Academic Children's Hospital, Academic Hospital, Uppsala;

From Switzerland: R. Angst, Kantonsspital Aarau; T. Kühne and M. Paulussen, University Children's Hospital, Basel; S. Leyvraz, Lausanne Cancer Centre, Lausanne; J. Rischewski, Luzerner Kantonsspital, Luzern; A. Feldges and J. Greiner, Ostschweizer Kinderspital, St Gallen, U. Hess, Clinical Centre, Medical Oncology, S. Gallen; G.U. Exner, Orthopedic Hospital Balgrist, Zürich; F. Niggli, University Children's Hospital, Zürich; A. Knuth, University Hospital, Medical Oncology, Zürich;

From United Kingdom: D. King and H. Bishop, Royal Aberdeen Children's Hospital, Aberdeen; A. McCarthy, Royal Belfast Hospital for Sick Children, Belfast; P. Henry, Belfast City Hospital, Belfast; B. Morland, Birmingham Children's Hospital, Birmingham; H. Rees, University Hospitals Bristol NHS Foundation Trust, Bristol; J. Nicholson, Addenbrooke's Hospital, Cambridge; H. Traunecker, Children's Hospital for Wales, Cardiff; H. Wallace, Royal Hospital for Sick Children, Edinburgh; M. Ronghe and E. Simpson, Royal Hospital for Sick Children, Glasgow; F. Cowie and J. White, NHS Greater Glasgow and Clyde-Western Infirmary, Glasgow; S. Picton and I. Lewis, Leeds General Infirmary, Leeds; M. Leahy, D Stark and PJ. Selby, St James University Hospital, 
Leeds; D. Heney and E. Ross, Leicester Royal Infirmary, Leicester; B. Pizer and H. McDowell, Royal Liverpool Children's Hospital NHS Trust, Alder Hey, Liverpool; A. Michalski, Great Ormond Street Hospital for Children, London; J. Whelan, University College Hospital NHS Trust, London; J. Chisholm and K. Pritchard-Jones, Royal Marsden NHS Trust, London; I. Judson, Royal Marsden Hospital, London; B. Brennan, Royal Manchester Children's Hospital and The Christie NHS Foundation Trust, Manchester; J. Hale and Q. Campbell-Hewson, Royal Victoria Infirmary, Newcastle upon Tyne; M. Verrill, Newcastle Upon Tyne, Newcastle; D. Walker, Queens Medical Centre, Nottingham University Hospitals NHS Trust, Nottingham; M. Sokal, Nottingham University Hospital NHS Trust, Nottingham; K. Wheeler, Oxford Radcliffe Hospitals, Oxford; V. Lee and M. Gerrard, Sheffield Children's Hospital, Sheffield; P. Woll, P. Lorigan and M. Robinson, Weston Park Hospital, Sheffield; J. Kohler and R. Ramanujachar, Southampton General Hospital, Southampton. 